\title{
A Proposed Ontology-Based Generic Context Model for Ubiquitous Learning
}

\author{
Benmesbah Ouissem, LRS Laboratory, University of Badji Mokhtar, Algeria \\ Mahnane Lamia, LRS Laboratory, University of Badji Mokhtar, Algeria \\ Mohamed Hafidi, LRS Laboratory, University of Badji Mokhtar, Algeria
}

\begin{abstract}
Context modeling is the keystone to enable the intelligent system to adapt its functionalities properly to different situations. As such, a representation mechanism that allows an adequate manipulation of this kind of information is required, and diverse approaches have been introduced; however, what takes more value and is being positioned as a standard is the ontology-based context modeling because it presents a common understanding vocabulary for a specific domain. Hence, it might be beneficial to have a generic ontology to model context in this area. However, according to diverse works, there is no proposal of a generic context model for context-aware learning. For addressing this problem, several existing context models are studied to identify the essentials of context modeling, whereby an ontology-based generic context model is presented. The proposed ontology is evaluated in two ways. Firstly, scenarios are used to justify the feasibility of the model; then a comparative study and evaluation metrics are applied to assess the proposal.
\end{abstract}

\section{KEYWORDS}

Adaptive Learning, Context Model, Context-Aware Learning, Generic Model, Hierarchical Model, Ontology, Ubiquitous Learning

\section{INTRODUCTION}

Ubiquitous learning (u-learning) can be seen as a new paradigm regarding deliver adaptation of learning services for learners. It aims to provide learners with the appropriate information, at the appropriate time, in the appropriate way, using mobile devices, wireless connection, and sensor technology (González et al., 2016). One essential feature to realize this type of smart learning is context awareness. A context-aware system is able to collect characteristics of the environment that surround the learner and respond to different changes (González et al., 2016). There has been a growing research background about the topic of context modeling and several approaches have been proposed (Yin et al., 2015), out of which ontology seem to be the most successful and promising one, this is due to the fact that it construct expressive models that can manage the required context information and offer some basic reasoning mechanisms. Another important purpose of ontology consists of providing a common understanding vocabulary for a specific field. For, it might be advantageous to have a generic ontology-based context model to unify contextual information in

\section{DOI: 10.4018/IJWLTT.20210501.oa4}

This article, published as an Open Access article on February 5, 2021 in the gold Open Access journal, International Journal of Web-Based Learning and Teaching Technologies (converted to gold Open Access January 1,2021), is distributed under the terms of the Creative Commons Attribution License (http://creativecommons.org/licenses/by/4.0/) which permits unrestricted use, distribution, and production in any medium, provided the author of the original work and original publication source are properly credited. 
the learning environment, however, according to several studies (Economide, 2009; González et al., 2016; Ennouamani \& Mahani, 2018; Yin et al., 2015), a large amount of works in the area of applying ontology within the e-learning field, address the personalization of learning objects based only on a subset of learners' context characteristics that is of interest in a particular learning scenario (Soualah-Alila et al., 2013; Naqvi et al., 2013; Salazar, 2014; Yin et al., 2015, Abech et al., 2016; González, 2014; Popović et al., 2016; Sevkli et al., 2017; Gómez et al., 2016; Skoulikari et al. 2015, Marcelo et al., 2016, Louhab et al., 2018, Aeiad \& Meziane, 2018). As such, there is no proposal of a generic context model for the context-aware u-Learning.

The lack of this kind of models is due to its complexity because it is considered a model, which has to handle all situations (Economide, 2009), in this case, the accuracy of the application based on this context is increased in parallel with its complexity and the requirements to collect data. Regarding (Economide, 2009, yin et al., 2015), there should be a balance between the number of contextual parameters, model complexity, and model accuracy, for that reason, it is necessary to reduce the context model's complexity by extracting useful context information.

In this article, the authors try to answer the following problem statement: which characteristics should be integrated into the proposed generic context model? In fact, the identification of the characteristics which effectively influence learning and which meet the learners' requirements becomes the most difficult end to achieve. This is because of the large number of context parameters. For that purpose, our research aims to contribute in the field of adaptive mobile learning by introducing a generic model for learners' context including the most common and frequently used characteristics within this field (Aguilar et al., 2018, Yin et al., 2015).

The reminder of this paper is articulated as follows. Section 2 analyzes several existing context models in u-Learning field, in order to conclude which characteristics should be involved in the model. Then the architecture of the proposed system is provided in section 3, it aims to show the position of the proposed generic Context model in the future system. Section 4 presents in details the proposed context model. Section 5, demonstrates the practicality and the richness of the proposed ontology through several scenarios and a comparative study. The conclusion of this work is introduced in Section 6.

\section{Related Works}

This section gives a brief background on Context modeling for Context-aware and adaptive Learning. The main purpose of this study is to extract the most commonly used context dimensions from the literature:

In (Das et al., 2010), the author describes a static context model for context aware E-Learning systems. The context is organized into three sub-contexts namely personal context, abstraction context and situation context that will not change in the entire learning course session. The model proposed in (Sampson \& Zervas, 2013), includes two main classes: learning context and mobile context. Learning context is related to the structure of learning design and learning activities. Mobile context is related to the ubiquitous and mobile environment, in which learners interact while performing those activities.

In (Soualah-Alila et al., 2013), the author presents an adaptive m-learning system that offers the most suitable learning activities to be carried out within an industrial training environment. Salazar in (Salazar, 2014) introduces a model of a multi-agent context-aware system that provides recommendations and personalized services. Another work presented by Yin (Yin et al., 2015) proposes a hierarchical context model, which emphasizes the characteristics of work-based learning. It consists of a common layer with a common ontology, and a specific domain layer, with a work-based learning generalized ontology and a specific work ontology. Abech in (Abech et al., 2016) proposes EduAdapt, an architectural model for the adaptation of learning objects considering some of the learners' context dimensions. To make this adaptation inferences and rules are used.

In (González, 2014), adaptation is realized by a set of predefined rules defined within the ontology. MTester (Popović et al., 2016) aims to use the learner's location in order to present the appropriate 
learning format. It allows the learner to display and review the courses in text format and to watch lectures through video streaming. In addition, the learner can take different tests with the possibility of answering by audio recording. Context4Learning (Marcelo et al., 2016) is an Android application that offers the possibility to adapt the learning path in order to meet the learners' specific needs. It allows the learner to identify when and where he is able to receive notifications for learning session. Shuib in (Shuib et al., 2015) presents I-Mol, which, aims to deliver adapted grammar learning contents, based on the learners' context. In addition to this, the application supports game-like applications (ranking game, poll, and quiz), learners' feedbacks, notifications and tips, getting reminders, participating in forums. Chookaew in (Chookaew et al., 2015) intends to adapt the learning path of the computer programming lessons based on the learning style as well as the knowledge level. This solution uses connections between the units of each lesson in order to determine the learning sequence.

The proposed system in (Wirawan \& Gitakarna, 2015) adapts the learning content, learning support, learning strategies, and learning flow according to a set of contextual information. The contribution in (Skoulikari et al. 2015), is intended to upgrade an open source traditional LMS capabilities focusing on mobile services adaptation and personalization. Gomez in (Gómez et al., 2014) presents a context-aware adaptive and personalized mobile learning system, which aims to support semi-automatic adaptation of the learning flow and the educational resources, tools and services that support the learning activities. A new context-aware mobile learning application is introduced in (Sevkli et al., 2017) to support and promote Hadith learning. This system uses context filtering based on regular expression and ontology matching recommending techniques.

The author in (Louhab et al., 2018) proposes an approach called Smart Enhanced Context-Aware for Flipped Mobile Learning BSECA-FML, which, aims to provide learners with an adapted course content format based on their mobile device context. Aiead in (Aeiad \& Meziane, 2018) presents a system called APELS to provide a personalized and adaptable learning environment to users from the freely available resources on the Web.

Table 1 shows the list of context parameters considered in the reviewed works.

We can notice from Table 1 the following points:

1. There are two types of contextual information:

a. A general context that characterizes all context-aware systems, it includes information that are related to user profile (not necessarily a learner), the properties of the environment: location, time, the technology used (mobile device, Network connection...), the physical activity of the user (running, sitting ...), and the physical conditions of the environment (noise level and light).

b. A specific context related to the field of e-learning, and which characterizes the situation of a user who has the quality of a learner: his/her learning style (visual, verbal, sequential, global ...), his/her knowledge level (beginner, intermediary or expert), his/her preferences (learn by video, audio, text...), concentration level... etc.

2. Each of the presented works provides an appropriate solution to a specific learning scenario, each model uses only some context dimensions and none of them has yet paid considerable attention to an effective solution that delivers all the desirable functionalities, this can be justified by the fact that increasing the number of contextual dimensions in a system increases the complexity of the system.

3. We can also notice a large number of contextual information appearing frequently; therefore they are common to several works (spatial-temporal dimension, the learner profile and the technological properties). In the specific context, the most used dimensions are knowledge level and the learning style.

4. The type of adaptation that learning systems provide has to be supported by pedagogical theories that can enhance the learning experience (Ouf et al., 2016). By reviewing the previous works, it was remarked that most of the works, ignore the contextual information that directly influence 
Table 1. Overview of the ontology based u- learning applications

\begin{tabular}{|c|c|}
\hline Ref & context information \\
\hline (Das et al., 2010) & $\begin{array}{l}\text { Personal context (learner's personal details, personality type and level of expertise of } \\
\text { the learner), abstraction context (preferences, learner's intention and learning style) and } \\
\text { situation context (learner's situation, network and device) }\end{array}$ \\
\hline $\begin{array}{l}\text { (Sampson \& Zervas, } \\
\text { 2013) }\end{array}$ & $\begin{array}{l}\text { Technology, User profile, Learning style, preferences, Location, Physical conditions } \\
\text { (Noise and luminosity level) }\end{array}$ \\
\hline $\begin{array}{l}\text { (Soualah-Alila et al., } \\
\text { 2013) }\end{array}$ & Location, Time, learning topic, social interaction \\
\hline (Salazar, 2014) & Location, Time, Technology (Device, network) \\
\hline (Yin et al., 2015) & Location, Time, Physical conditions (Noise level), technology, Concentration level \\
\hline (Abech et al., 2016) & $\begin{array}{l}\text { learner profile (personal information, education profile, knowledge level, interests and } \\
\text { preferences, learning style, and learning objectives), Location, Technology (screen size, } \\
\text { battery level, network signal strength) }\end{array}$ \\
\hline (González, 2014) & Location, Physical cdt (noise level, lighting level), activity, Technology \\
\hline (Popović et al., 2016) & learning progress, Location \\
\hline (Marcelo et al., 2016) & Location, Time, Physical activity, Learning progress \\
\hline (Shuib et al., 2015) & Learning style \\
\hline (Chookaew et al., 2015) & Learning style, needs, Knowledge level \\
\hline $\begin{array}{l}\text { (Wirawan \& Gitakarna, } \\
\text { 2015) }\end{array}$ & Learning style, knowledge level, Learning objective, learning progress, Preference \\
\hline (Skoulikari et al. 2015) & Learner profile, Learning style, Knowledge level, learning progress, Preferences \\
\hline (Gómez et al., 2016) & Location, time, user profile, Learning objective \\
\hline (Gómez et al., 2014) & Learner profile, time, activity, learning objects and location. \\
\hline (Sevkli et al., 2017) & User Profile, Time and location \\
\hline (Louhab et al., 2018) & Profile, learning style, knowledge level, technology, motions, location, physical cdt \\
\hline (Aeiad, Meziane, 2018) & Profile, Needs, Knowledge background, learning style \\
\hline
\end{tabular}

the pedagogical side like concentration level, the learning activities type as well as teaching methods. Moreover, none of these models considers the learners' satisfaction, which is a very important aspect that can drive them to stop using the application.

In brief, the determination of the factors that effectively build the context model is a very important step (Ennouamani \& Mahani, 2018; Aguilar et al., 2016). Based on our study, it is clear that in the one hand, there are a lot of features about the learners' context that are frequently used in different learning scenarios and in the other hand, there are other important features that make a successful adaptation have been ignored. Therefore, this paper uses ontology to create and introduce a generic context model that gathers the two types of context in order to contribute in an adaptive and personalized learning environment.

\section{Proposed System Architecture}

As viewed in the previous sections, the main objective behind this research is to address the concept of adaptation by introducing learners with suitable learning objects (LO) based on their context. In order to show the position of the proposed generic context model within the future context-aware 


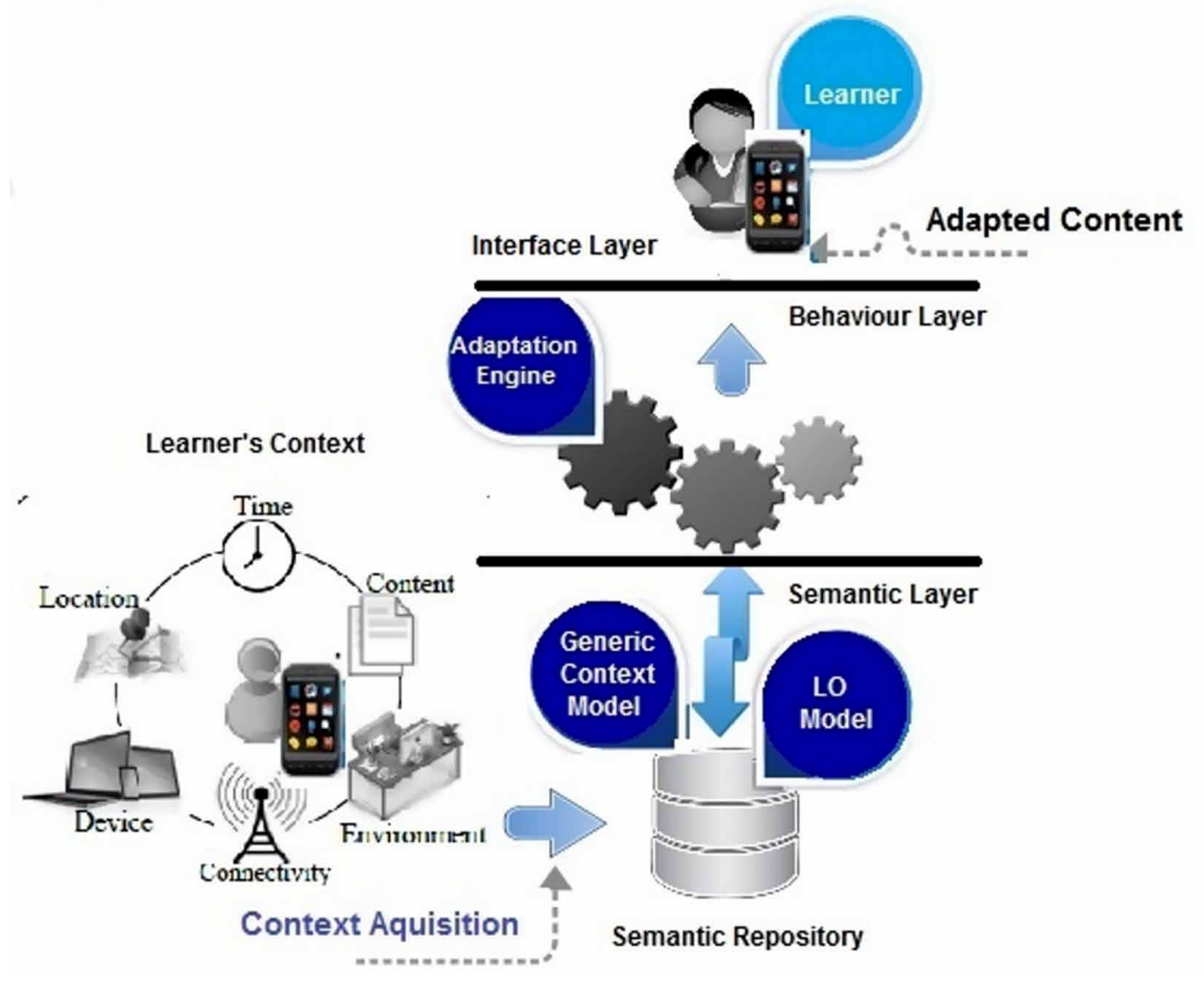

learning system, a general architecture is presented in this section; this architecture is based on three principal components (see Figure 1):

1. Interface Layer: Shows the retrieved learning Object (LO). The components of this layer implement the functionalities required to permit learners to use the Context aware learning system. It provides the learner with personalized learning content.

2. Semantic Layer: Integrates context model ontology and learning object (LO) ontology. These components are represented using web ontology language OWL. LO model is a set of structured knowledge that converts a real world part into an abstract representation. It is a structured content related to a specific domain.

3. Behavior Layer: This model is the bridge between the context and the LO models, it works by combining learners' context with the metadata of the learning materials. It includes predefined adaptation rules and functions that help to select the appropriate pedagogical materials in the LO model and to determine when and how to deliver it.

\section{PROPOSED GENERIC CONTEXT MODEL FOR U-LEARNING}

\section{Proposed Framework}

In order to create a generic context model adapted to any scenario in the field of Context aware learning, it is necessary to develop an ontology that captures generic concepts to a higher level and be able to provide mechanisms to extend the specific information of a context in a hierarchical 
Figure 2. A generic context model framework

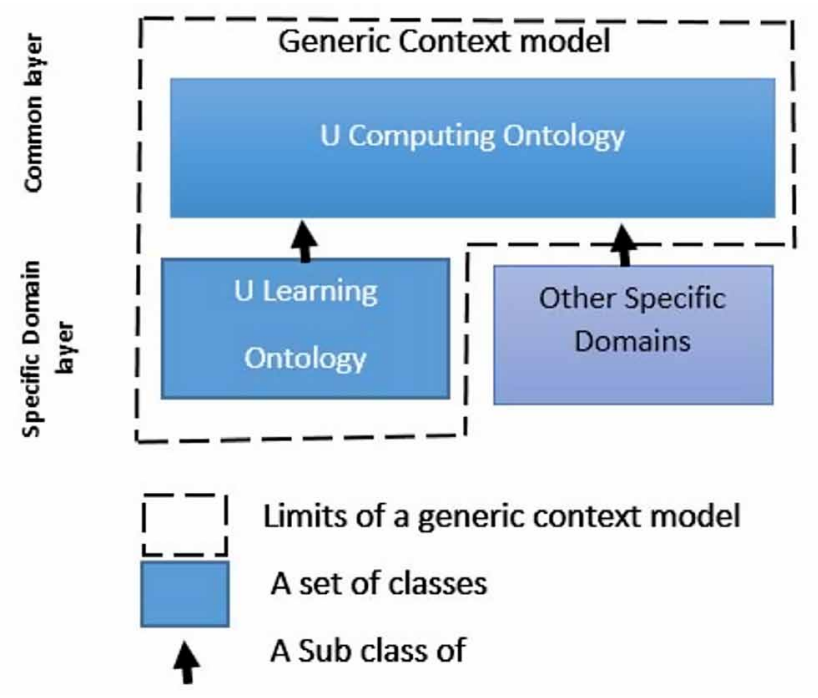

manner (Aguilar et al., 2018). According to our study, contextual information can be classified in two categories: the first, grouping general information in the domain of u-computing, such as User, location, time, activity, and technical characteristics. The second category includes specific information relative to the field of learning, such as learning style, Knowledge level... Within this vision, the proposed model is characterized by two hierarchical levels (see Figure 2). The first one is general and common domain ontology, that will be shared among different particular domains and the second one is particular domain ontology which, inherits and specifies the common ontology and captures contexts of a specific domain (transportation, medical service, etc.), in our case the learning domain.

\section{Description of the Ontology Used to Build the Generic Model}

There are several techniques to model learners' context, however, what takes more value and is being positioned as a standard is the Ontology-Based Context Modeling (Ouf et al., 2017; Aguilar et al., 2018; González et al.; 2016). To develop our ontology, we are basing the development process on two methodologies: METHONTOLOGY (Fernández-López et al., 1997) and Noy and McGuiness's method (Noy \& McGuinness, 2001). Figure 3 shows a general representation of the proposed generic context model for u-learning. It describes the hierarchical classification of classes and subclasses. Four steps are followed to create our ontology, step1 creates classes and class hierarchy, step 2 determines object properties, step3 determines ontology instances, and step 4 is dedicated to ontology reasoning. In this paper, only the two first steps are considered.

Step1 - Creates Class Hierarchy: Classes and properties that form the proposed model are extracted from the related works section presented previously; therefore, these entities are the most common elements of the major works in the field of context aware learning.

All concepts related to learners' context are determined and organized in two layers:

- Common layer (Ubiquitous computing level): Defines four main classes: User, Activity, Environment, and Technology. Its implementation in Protégé is shown in Figure 4. 
Figure 3. Hierarchical design of the proposed generic context model

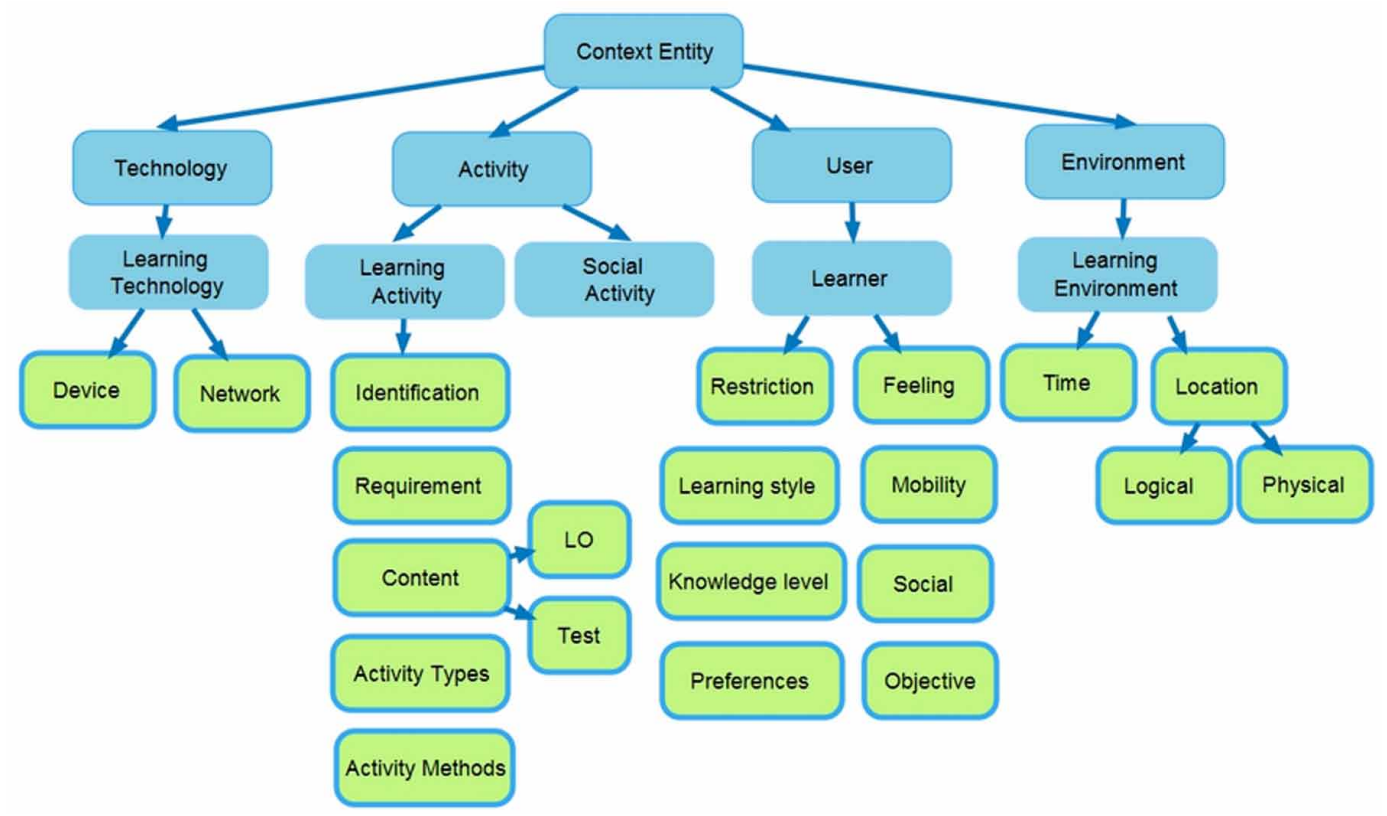

Figure 4. Step1. Common layer

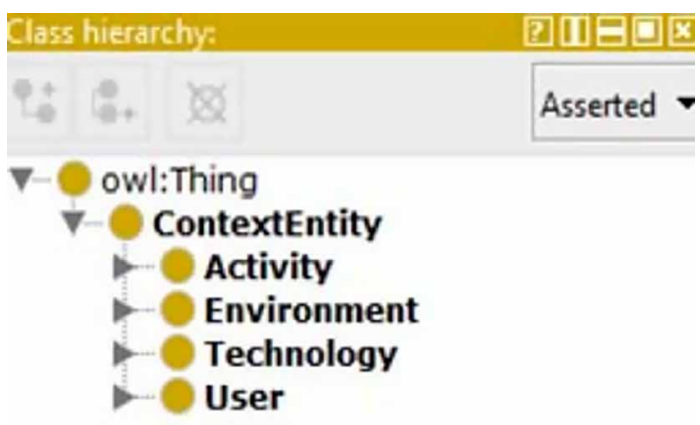

- Specific domain layer: Extends five main classes from the higher level as shown in Figure 5 with their hierarchy of sub classes:

- Learner State: Learner Identity, Learner Mobility (Sitting, Standing, Walking) Learner Feeling (Feedback, satisfaction), Learner preferences, Learner objective, restrictions (Time and location restriction), learning style (Visual, Verbal,...), knowledge level (Beginner, Experienced, Expert) and social relations (see Figure 6)

- Learning Technology: Device, Network (see Figure 6) 
Figure 5. Step1. Specific domain layer

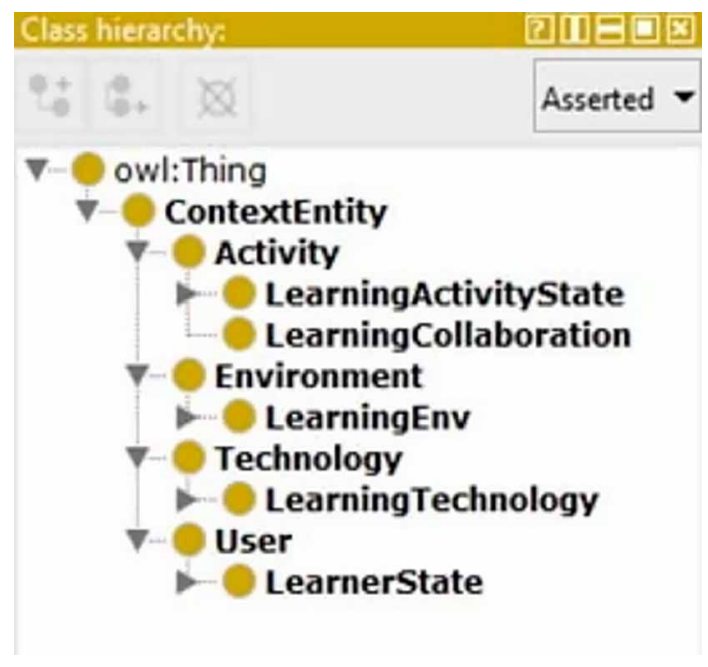

- Learning Environment: Time, Location (see Figure 6)

- Learning Activity: Identification, Requirement, Content (LO, Test), (see Figure 7) Activity Types (see Figure 7) and Teaching Method Types (see Figure 7).

- Social Activity

\section{Step2 - Determine Object Properties,}

The object properties, which represent relationships among the main classes of the proposed generic context model, are shown in Figure 8 and 9.

Figure 10,11, 12 and 13, show the relationships between respectively the main classes User, Environment, Technology, Activity and their hierarchies.

\section{EVALUATION OF THE PROPOSED ONTOLOGY}

Ontology evaluation is an important step within the ontology development process (Abech et al., 2016). Although there are many ontology evaluation propositions, there is no an agreed on a straightforward method for evaluating and comparing ontologies (Abech et al., 2016). In this section, two main strategies are applied. The first strategy evaluates the proposed ontology through a set of

Figure 6. A. Learner state, B. Learning technology C. Learning environment
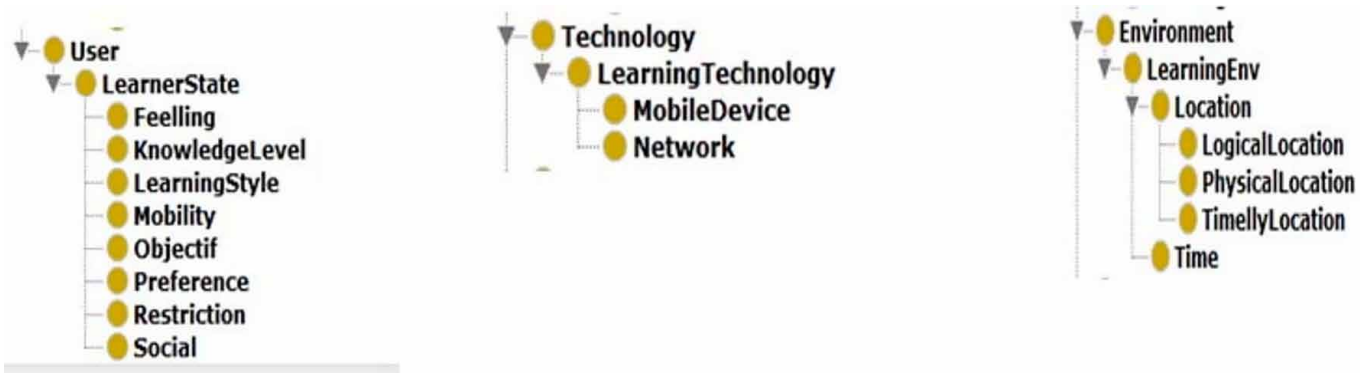
Figure 7. A. Learning activity B. Activity type C. Method types

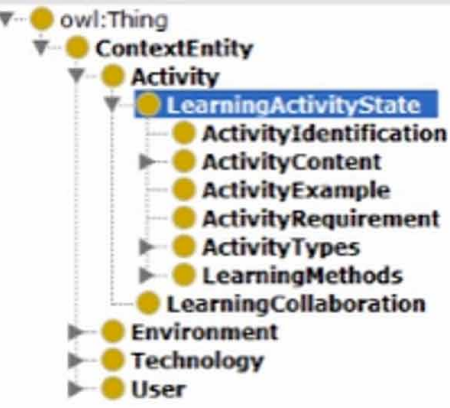

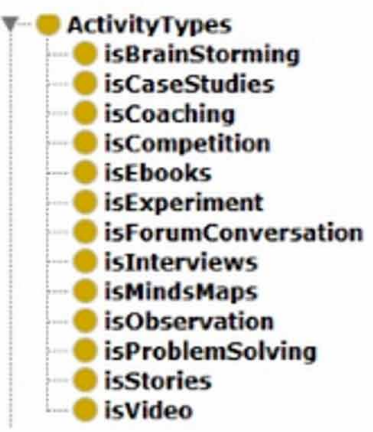

Figure 8. Main relationships between classes

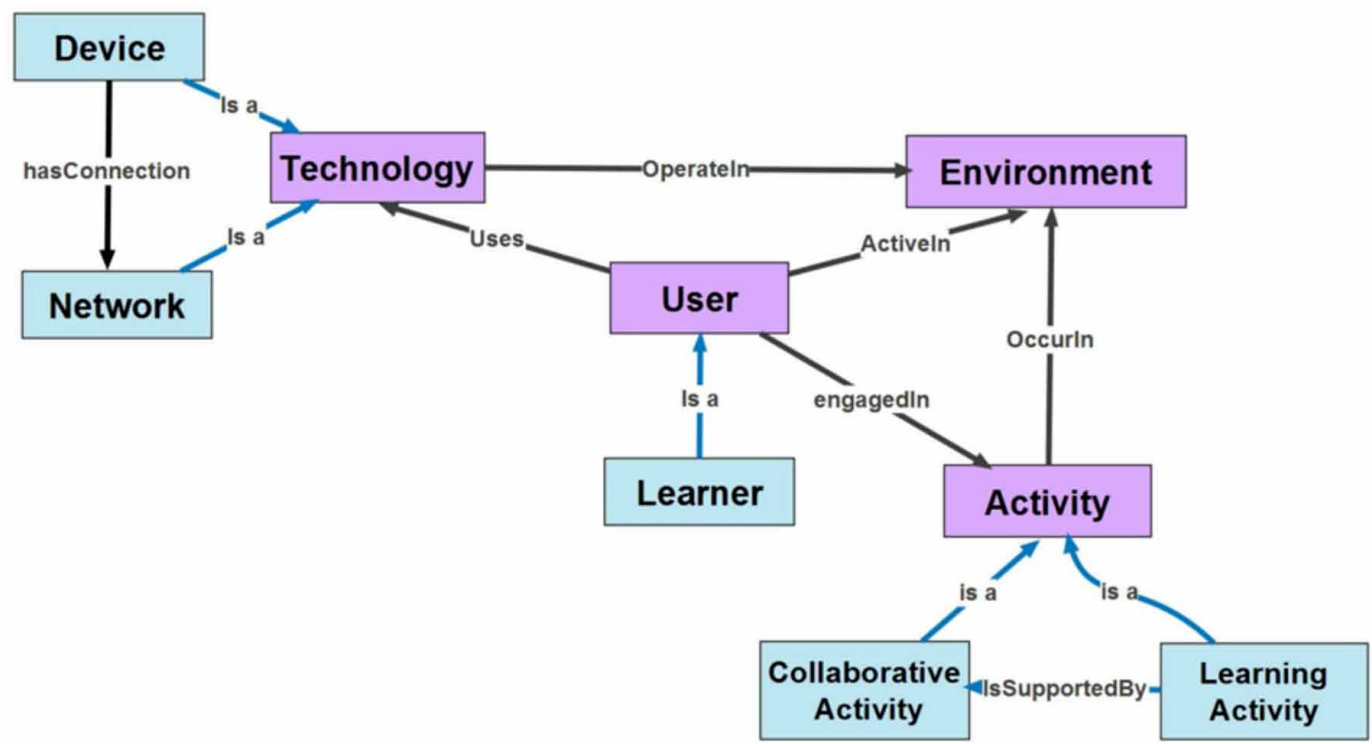

scenarios. The second one evaluates the model by using some metrics and comparison with other similar ontologies.

\section{Scenario Based Evaluation}

The scientific community has used scenarios to evaluate context awareness. In this section, four scenarios are presented to evaluate the behavior of the proposed ontology. For each scenario, an SWRL (Semantic web Rule Language) rule is created in order to suggest the most appropriate LO. SWRL is an important formalism for expressing knowledge in the form of rules (Ye et al., 2015):

- Scenario 1: The learner is using his Smartphone. He wants to learn a specific topic. The device has a low level of battery and the network connection is 3G. Learner's learning style was detected as Visual and verbal. By detecting that situation, the system sends an appropriate learning object, in this case, a video, according to the learner's context. 
International Journal of Web-Based Learning and Teaching Technologies

Volume 16 • Issue 3 • May-June 2021

Figure 9. Main object properties in protégé

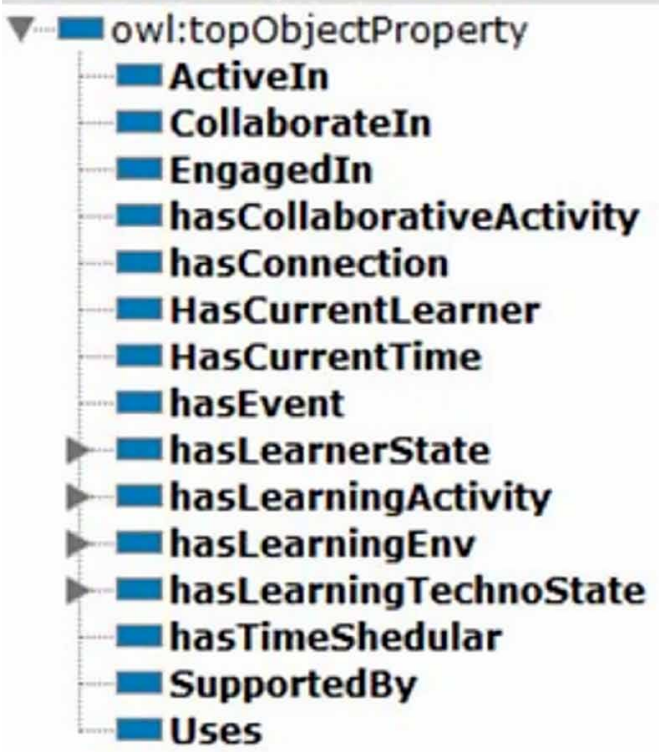

Figure 10. User dimension

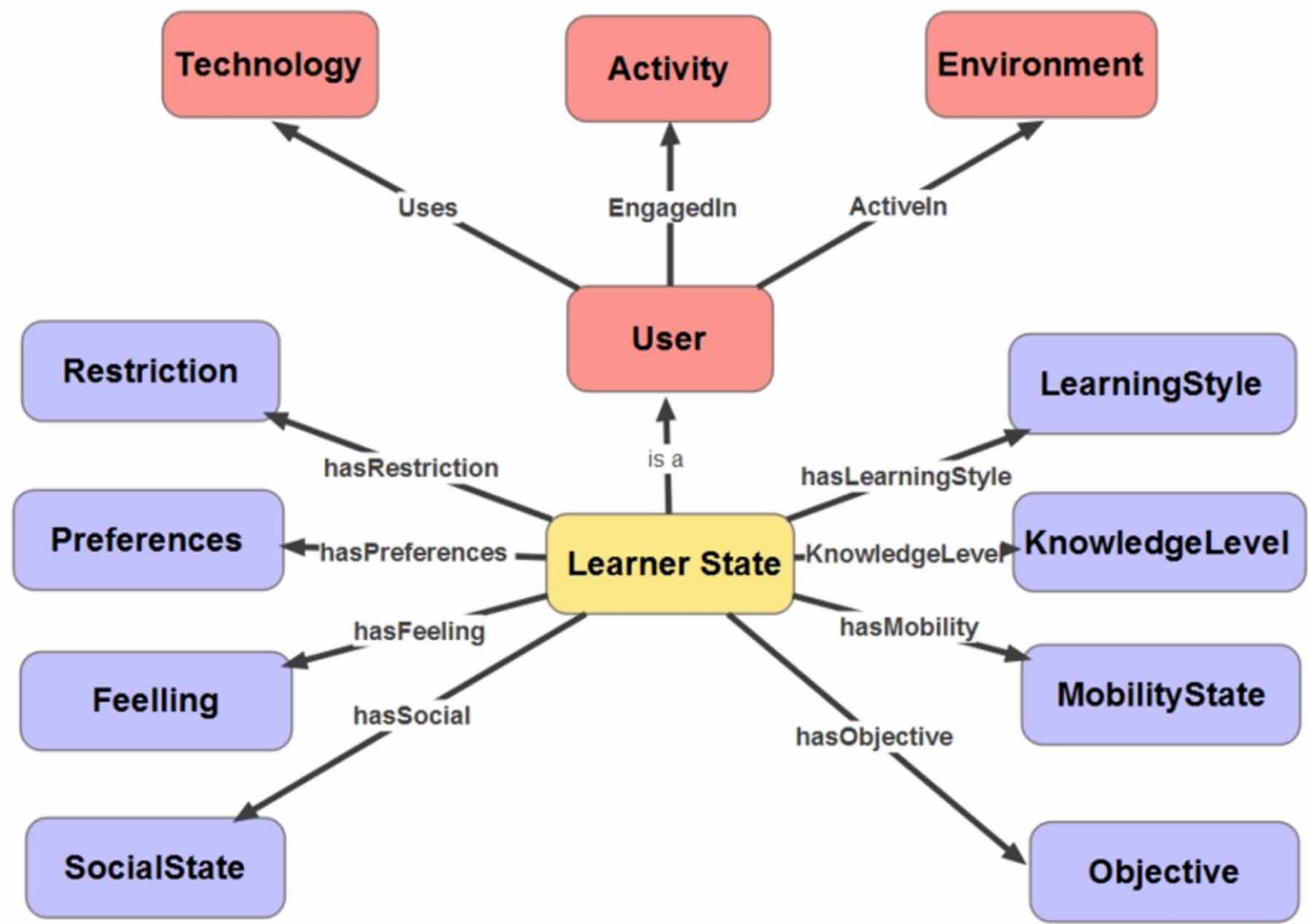




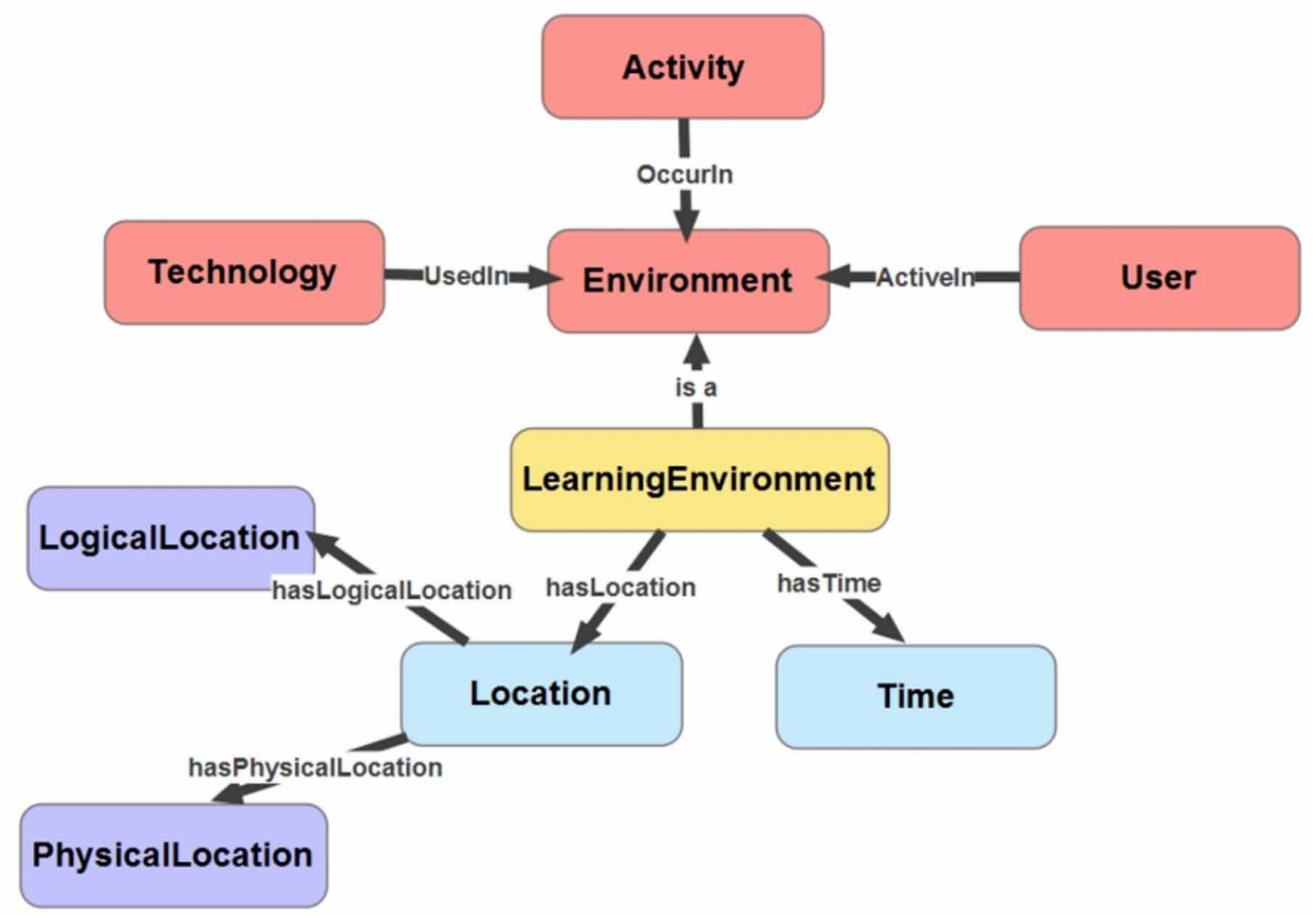

Figure 12. Technology dimension

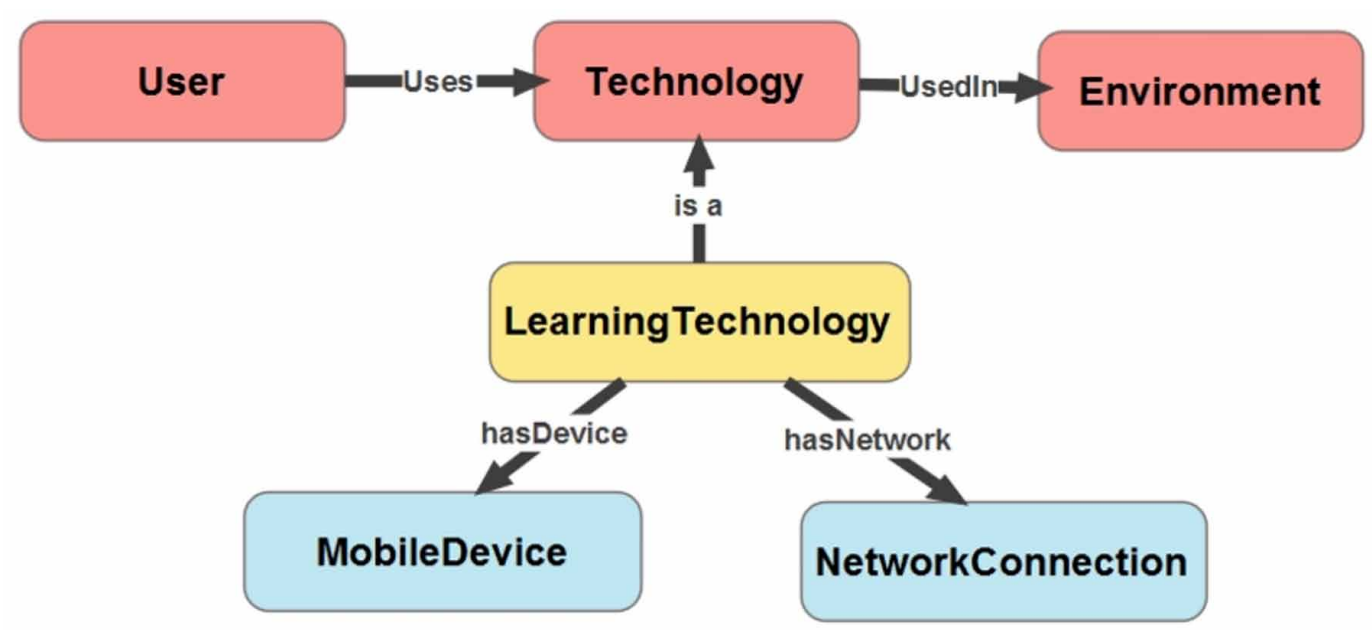


Figure 13. Activity dimension

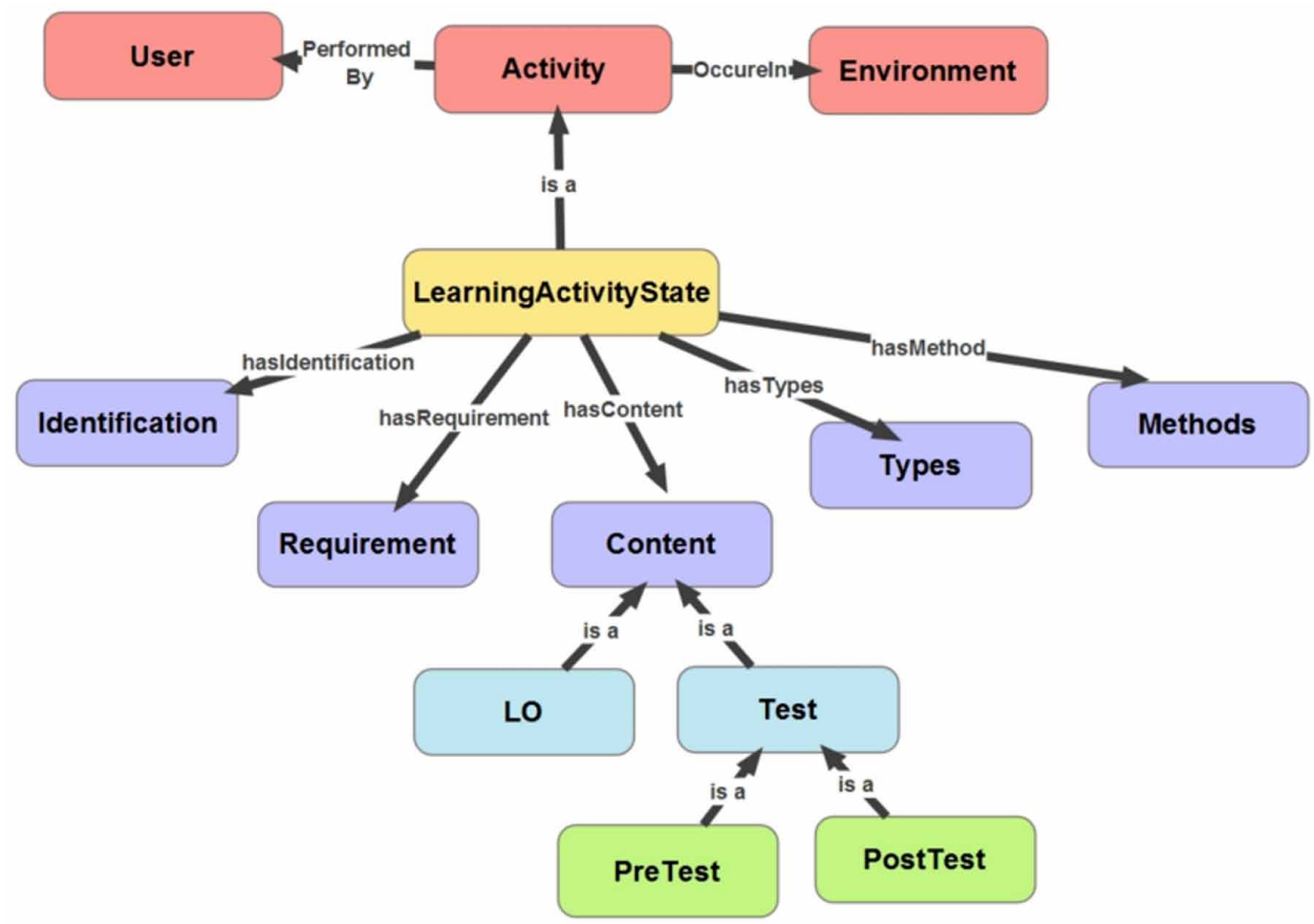

The property hasNeedKeyword identifies the needs that the learners have. With this knowledge, the system will query LOs that attend to these keywords. SuportedConnectionLevel is triggered using ConnectionType, to indicate that the media of the selected LO supports low connection in the case of $3 \mathrm{G}$. This allows choosing the most adequate media to learner's connection type detected on the device (see Figure 14).

- Scenario 2: In this scenario, we illustrate the use of the proposed ontology in the field of work-based learning, the learner needs to learn how to configure Tcp/ip address in Linux, his Smartphone has a high battery level and the network connection is wifi, his available time to learn is $15 \mathrm{mn}$, his learning style is "Visual". In addition to this, the learner has passed a pretest, which allowed him to be considered as a beginner. According to this context, the learning system presents to him a set of adequate LOs, for example, a media player is called to play a video appropriate to a beginner, and does not exceed $15 \mathrm{mn}$, about the requested topic (see Figure 15).

\section{Figure 14. Rule Associated to Scenario 1}

Learner (?x), LO (?y), Uses (?x, ?d), deviceType (?d, "Smartphone"), BatteryLevel (?d, "Low"), ConnectionType (?d, "3G"), hasLOMediaType (?y, ?m), BatteryLevelSupported(?m, "Low"), ConnectionLevelSupported (?m, "Low"), mediaSendToSmartphone (?m, "True"), hasNeedKeyword(?x, ?T), haskeyword (?y, ?T), hasLearningStyle (?x, ?S), hasStyle (?y, ?S) $\rightarrow$ hasAssignedLo (?x, ?y) 
Learner (?x), LO (?y), Uses (?x, ?d), BatteryLevel (?d, "High"), ConnectionType (?d, "Wifi"), hasLOMediaType (?y, ?m), supportedBattteryLevel (?m, "High"), supportedConnectionLevel (?m, "High"), hasNeedKeyword (?x, ?T), hasKeyword (?y, ?T), hasLearningStye (?x, "Visual), hasStyle (?y, "Video"), hasKnowledgeLevel (?x, "Beginner"), hasDifficultyLevel (?y, "Easy"), hasAvailableTime (?x, "15"), hasLODuration(?y, "15") $\rightarrow$ hasAssignedLO (?x, ?y)

hasDifficultyLevel, presents the LO's difficulty level that better match the Knowledge level of the current learner

- Scenario 3: A learner, driving her car to the University, may need information regarding the course in which she will have an examination in a few minutes $(30 \mathrm{mn})$. Since the learner is currently driving, the object can be adapted to audible format and to the time remaining before the exam (see Figure 16).

The property hasMobilityState defines the activity type that the learner is doing at the moment. In this case, the learner is driving. This information is obtained from the Accelerometer.

- Scenario 4: The last example of using SWRL Rules in our proposed model aims to infer the type of learning activity based on the learning style of the learner. According to Table 2, there is a relation between learners learning style and learning Activity type. Taking as an example, Sequential learner, who likes to learn in specific, sequenced and small Steps and applies logical stepwise paths in solving problems, the most suitable learning activity type for this category of learners, is case Study (see Figure 17).

\section{METRIC-BASED EVALUATION}

\section{Metrics}

The metrics are organized into two related categories: schema metrics and instances metrics. The first category evaluates ontology design and its potential for rich knowledge representation. The second category evaluates the way data is placed within ontology. As we have explained before, this design

Figure 16. Rule associated to scenario 3

Learner (?x), LO (?y), hasMobilityState (?x, "driving"), hasAvailableTime (?x, "30") , hasNeedKeyword(?:x ?z), hasLOKeyword (?y, ?z), hsLOFormat (?y, "Audio"), hasDelay (?y, "30") $\rightarrow$ hasAssignedLO (?x,?y)

Figure 17. Rule associated to scenario 4

Leamer $(? \mathrm{x}) \wedge$ hasLeamingStyle $(? \mathrm{x}, \text { Sequential })^{\wedge}$ LeamingActivity $(? \mathrm{z}) \wedge$ isEngagedIn $(? \mathrm{x}, ? \mathrm{z}) \rightarrow$ hasActivityType $(? \mathrm{z}$, CaseStudy). 
Table 2. The Learning Style Model According to Felder Silverman Standard (Ouf et al., 2017)

\begin{tabular}{|l|l|}
\hline \multicolumn{1}{|c|}{ Learning style } & \multicolumn{1}{c|}{ Recommended activities } \\
\hline Sensing & Case studies, Problem solving, Discussion, Brainstorming \\
\hline Intuitive & Brainstorming, Experiments \\
\hline Visual & Observing, Graphic organizers, Video, Illustrated reading, mind maps \\
\hline Verbal & Discussion, Reading activity, Role Plays, Crosswords, Puzzles, Case Studies \\
\hline Active & Brainstorming, Discussion, Group Work, Experiments,, Problem Solving, Puzzles \\
\hline Reflective & E-books, discussions, Feedback, Interviews, Listening to lectures, Personality questionnaires. \\
\hline Sequential & Case Studies \\
\hline Global & Consulting references, Discussion \\
\hline
\end{tabular}

work is essentially centered around the first two steps of the conceptualization phase, which are the creation of a hierarchy of classes and relations between these classes, for that we are convinced that Schema metrics are the most adequate to assess our ontology.

We used the methodology described in (Abech et al., 2016), which is based on FOEval model (Bouiadjra \& Benslimane, 2011) to evaluate the proposed context ontology. FOEval (Bouiadjra \& Benslimane, 2011) consists in a group of schema metrics that assist the evaluation of local or remote ontologies. We employed the metrics richness as proposed in FOEval. Ontology richness can be measured on different levels:

- Relation Richness (rR): is the metric that reflects the diversity of relations and placement of relations in the ontology. The ontology that has more relationships (composition), instead of inheritances (specializations), is considered richer than the taxonomy with the opposite characteristic. $r R$ is defined as the ratio of the number of non-hierarchical relationships $s P$, divided by the number of all relationships $P$.

- Attribute Richness (aR): The metric $a R$ is used to denote the amount of information stored by the ontology. This metric determines that the more attributes are defined in the ontology, the better will be the presented knowledge. The attribute richness $(a R)$ is defined as the ratio between the number of attributes defined for all classes (att) and the number of classes $C$.

- Ontology Richeness (oR): This metric can be used in comparison with other ontologies, in order to determine how the value of oR is significant. It is defined as the sum of relationship richness $(\mathrm{rR})$ and attribute richness $(\mathrm{aR})$.

- Subclass Richness $(\boldsymbol{s} \boldsymbol{R})$ : or Inheritance Richness $(i R)$ reflects the distribution of information across different levels of the ontology (Bouiadjra \& Benslimane, 2011), This is a good indication of how well knowledge is grouped into different categories and subcategories in the ontology. The calculation of the $\mathrm{sR}$ is the ratio between the number of subclass $(s C)$ by the sum of the number of classes $C$ and subclass.

\section{Comparative Analysis}

As a golden standard, we used two ontologies described in (Pernas et al., 2012) and (abech et al., 2016). Our choice is based on two reasons: The first one is that, both works have many similarities with our ontology in conceptual terms; they aim to propose an ontology-based context model to be used within an adaptive and personalized learning system. The second reason and the most important is that Abech (abech et al., 2016) has integrated in his work, an evaluation section of his ontology, and she has used the same metrics described in Foeval (Bouiadjra \& Benslimane, 2011). Abech chose 
the work presented in (Pernas et al., 2012) as Golden standard because it allows access to his OWL files. This will allow us to exploit directly the data of the two works that are presented in Abech Evaluation section (abech et al., 2016)

The metrics in Table 3 are extracted from the software Protégé, and they are used to calculate the Attribute Richness (aR) and the Relation Richness (rR) as proposed in FOEval (Bouiadjra \& Benslimane, 2011). After that, these two metrics were used to estimate the Ontology Richness (oR) (Bouiadjra \& Benslimane, 2011).

Table 4 summarizes the metrics in concordance with the FOEval model (Bouiadjra \& Benslimane, 2011), comparing the metrics of the proposed Ontology and the ontologies described in (Pernas et al., 2012; Abech et al., 2016).

The results for our ontology are 0.51 for $\mathrm{rR}$ and 1.27 points for $\mathrm{aR}$. These two results indicate that the context ontology defined in this work is richer in attributes than relations. The value of aR obtained in the proposed ontology is better if compared to the two golden standard Ontologies, as it's defined in Foeval (Bouiadjra \& Benslimane, 2011), the more attributes are defined in ontology, the better will be the knowledge that the ontology represents.

The value of the metric $\mathrm{rR}$ is the smallest compared to other ontologies, it means that the number of hierarchical relations defined in our ontology is more interesting than the number of non-hierarchical relations, this can be explained by the fact the proposed ontology is an hierarchical model based on 2 levels so the relationships that link the concepts of the two levels are hierarchical in nature.

Adding both metrics we can obtain oR metric, which is 1.78 points. oR value is determinant to affirm that the compared ontology is richer and has more information (contains more attributes and relationships). We can notice from Table 4, that the value of oR of the proposed ontology is more interesting than (Pernas et al., 2012) and (Abech et al., 2016), this is because the scope of the generic ontology is wider than the scope of two golden standards ontologies.

The Subclass Richness (sR) indicates how well knowledge is grouped into different categories and subcategories in the ontology. According to table 4, the value of sR is 0.98 ; this result indicates that our ontology, exceeds the other two golden standard ontologies in the distribution of knowledge between different concepts and sub concepts. Moreover, an ontology with a high

Table 3. Metrics of the proposed ontology and the golden standard works

\begin{tabular}{|l|l|l|l|}
\hline & Abech 2016 & Pernas 2012 & The proposed Ontology \\
\hline Total number of Object property & 15 & 71 & 60 \\
\hline Total number of sub Object property & 2 & 22 & 44 \\
\hline Total number of Data property & 25 & 39 & 84 \\
\hline Total number of classes & 28 & 52 & 66 \\
\hline Total number of sub classes & 2 & 31 & 65 \\
\hline
\end{tabular}

Table 4. Comparison between the three ontologies

\begin{tabular}{|l|l|l|l|}
\hline & \multicolumn{1}{|c|}{ Abech 2016 } & \multicolumn{1}{c|}{ Pernas 2012 } & \multicolumn{1}{c|}{ The Proposed Ontology } \\
\hline rR & 0.88 & 0.69 & 0.51 \\
\hline aR & 0.89 & 0.75 & 1.27 \\
\hline oR & 1.77 & 1.44 & 1.78 \\
\hline sR & 0.06 & 0.37 & 0.98 \\
\hline
\end{tabular}


sR would be of a horizontal nature, which means that the proposed ontology represents a wide range of general knowledge.

\section{CONCLUSION AND PERSPECTIVES}

In this paper, we have addressed a significant research issue related to learner's context modeling in an adaptive learning environment; all context models deal only with a subset of context information that is of interest in a specific scenario. As such, there is no proposal of a generic context model that helps to capture a learner's context in its entirety. The presence of such a model will unify the different contextual concepts, thus constituting a reference to multiple works that operate in this area. Hence, in an open environment, it is difficult to define a 'complete' model of context, without a priori knowledge of the applications that will use it. In fact, the identification of the characteristics which effectively influence learning and which meet the learners' requirements becomes a research problem. For addressing this issue, a literature study is presented in order to define the main concepts of the generic model; from this study, it was clear that in the one hand, there are a lot of features about the learners' context that are frequently used in different learning scenarios and in the other hand, there are other important features that make a successful adaptation have been ignored. Therefore, this paper proposes a generic context model that helps to capture the two types of context and organizing them into an appropriate structure.

Furthermore, the proposed ontology is evaluated by presenting several scenarios. Additionally, the metrics Richness allowed a comparison of the proposed ontology with two golden standard works, a reference for our proposal.

This contribution is still in progress. In future works, we are going to test the creation and integration of domain-specific ontologies, in order to observe how the proposed ontology could be adapted in real time. 


\section{REFERENCES}

Abech, M., Costa, C. A., Barbosa, J. L., Rigo, S. J., \& Rosa Righi, R. (2016). A model for learning objects adaptation in light of mobile and context-aware computing. Personal and Ubiquitous Computing, 20(2), $167-184$. doi:10.1007/s00779-016-0902-3

Aeiad, E., \& Meziane, F. (2018). An adaptable and personalised E-learning system applied to computer science Programmes design. Education and Information Technologies, 1-25.

Aguilar, J., Jerez, M., \& Rodríguez, T. (2018). CAMeOnto: Context awareness meta ontology modeling. Applied Computing and Informatics, 14(2), 202-213

Bouiadjra, A. B., \& Benslimane, S. M. (2011, November). FOEval: Full ontology evaluation. In 2011 th International Conference on Natural Language Processing and Knowledge Engineering (pp. 464-468). IEEE.

Chookaew, S., Wanichsan, D., Hwang, G. J., \& Panjaburee, P. (2015). Effects of a personalised ubiquitous learning support system on university students' learning performance and attitudes in computer-programming courses. International Journal of Mobile Learning and Organisation, 9(3), 240-257. doi:10.1504/IJMLO.2015.074207

Das, M. M., \& Chithralekha, T., \& SivaSathya, S. (2010). Static context model for context aware e-learning. International Journal of Engineering Science and Technology, 2(6), 2337-2346.

Economides, A. A. (2009). Adaptive context-aware pervasive and ubiquitous learning. International Journal of Technology Enhanced Learning, 1(3), 169-192. doi:10.1504/IJTEL.2009.024865

Ennouamani, S., \& Mahani, Z. (2018). Designing A Practical Learner Model For Adaptive And Context Aware Mobile Learning Systems. International Journal of Computer Science and Network Security, 18(4), 84-93.

Fernández-López, M., Gómez-Pérez, A., \& Juristo, N. (1997). Methontology: From ontological art towards ontological engineering. Academic Press.

Gómez, J. E., Huete, J. F., \& Hernandez, V. L. (2016). A contextualized system for supporting active learning. IEEE Transactions on Learning Technologies, 9(2), 196-202. doi:10.1109/TLT.2016.2531685

Gómez, S., Zervas, P., Sampson, D. G., \& Fabregat, R. (2014). Context-aware adaptive and personalized mobile learning delivery supported by UoLmP. Journal of King Saud University-Computer and Information Sciences, 26(1), 47-61. doi:10.1016/j.jksuci.2013.10.008

González, G. (2014). Ontología del perfil de usuario para personalización de sistemas de u-learning universitarios. In XLIII Jornadas Argentinas de Informática e Investigación Operativa (43JAIIO)-XVII Concurso de Trabajos Estudiantiles. EST.

González, G., Durán, E., \& Amandi, A. (2016, November). Context ontologies in ubiquitous learning environments. In Ibero-American Conference on Artificial Intelligence (pp. 391-403). Springer.

Hsu, T. Y., Ke, H. R., \& Yang, W. P. (2006). Knowledge-based mobile learning framework for museums. The Electronic Library, 24(5), 635-648. doi:10.1108/02640470610707240

Louhab, F. E., Bahnasse, A., \& Talea, M. (2018). Considering mobile device constraints and context awareness in adaptive mobile learning for flipped classroom. Education and Information Technologies, 23(6), 2607-2632. doi:10.1007/s10639-018-9733-3

Marcelo, C., \& Yot-Domínguez, C. (2016). Learning in mobility with Context4Learning: Developing a contextaware mobile learning application. International Journal of Mobile Learning and Organisation, 10(4), $203-222$. doi:10.1504/IJMLO.2016.079497

Martín, E., Carro, R. M., \& Rodríguez, P. (2006, October). A mechanism to support context-based adaptation in m-learning. In European Conference on Technology Enhanced Learning(pp. 302-315). Springer. doi:10.1007/11876663_24

Naqvi, N. Z., Preuveneers, D., \& Berbers, Y. (2013). Cloud computing: a mobile context-awareness perspective. In Cloud Computing (pp. 155-175). Springer. doi:10.1007/978-1-4471-5107-4_8

Noy, N. F., \& McGuinness, D. L. (2001). Ontology development 101: A guide to creating your first ontology. Academic Press. 
Ouf, S., Ellatif, M. A., Salama, S. E., \& Helmy, Y. (2017). A proposed paradigm for smart learning environment based on semantic web. Computers in Human Behavior, 72, 796-818. doi:10.1016/j.chb.2016.08.030

Pernas, A. M. (2012). Enriching adaptation in e-learning systems through a situation-aware ontology network. Interactive Technology and Smart Education, 9(2), 60-73. doi:10.1108/17415651211242215

Popović, O., Marković, D. S., \& Popović, R. (2016). mTester-Mobile learning system. Computer Applications in Engineering Education, 24(3), 412-420. doi:10.1002/cae.21719

Qazi, N. I., \& Qadir, M. A. (2010, June). Algorithms to evaluate ontologies based on extended error taxonomy. In 2010 International conference on information and emerging technologies (pp. 1-6). IEEE.

Salazar Ospina, O. M. (2014). Modelo de Sistema Multi-Agente ubicuo, adaptativo y sensible al contexto para ofrecer recomendaciones personalizadas de recursos educativos basado en ontologías (Doctoral dissertation). Universidad Nacional de Colombia-Sede Medellín.

Sampson, D. G., \& Zervas, P. (2013). Context-aware adaptive and personalized mobile learning systems. In Ubiquitous and mobile learning in the digital age (pp. 3-17). Springer. doi:10.1007/978-1-4614-3329-3_1

Sevkli, A. Z., Motiwalla, L., \& Abdulkarem, H. F. (2017). The design and implementation of a context-aware mobile hadith learning system. International Journal of Mobile Learning and Organisation, 11(4), $295-313$. doi:10.1504/IJMLO.2017.087064

Shuib, M., Abdullah, A., Azizan, S. N., \& Gunasegaran, T. (2015). Designing an intelligent mobile learning tool for grammar learning (i-MoL). International Journal of Interactive Mobile Technologies, 9(1), 41-46. doi:10.3991/ijim.v9i1.4238

Skoulikari, A. I., Tsakalidis, A., \& Tsolis, D. (2015, July). Personalized and adaptive mobile elearning for cultural education. In 2015 6th International Conference on Information, Intelligence, Systems and Applications (IISA) (pp. 1-6). IEEE. doi:10.1109/IISA.2015.7387968

Soualah-Alila, F., Mendes, F., \& Nicolle, C. (2013). A context-based adaptation in mobile learning. IEEE Computer Society Technical Committee on Learning Technology, 15(4), 5.

Wirawan, I. M. A., \& Gitakarna, M. S. (2015). Development of adaptive mobile learning (AML) On information system courses. International Journal of Advanced Computer Science and Applications, 6(12).

Ye, J., Dasiopoulou, S., Stevenson, G., Meditskos, G., Kontopoulos, E., Kompatsiaris, I., \& Dobson, S. (2015). Semantic web technologies in pervasive computing: A survey and research roadmap. Pervasive and Mobile Computing, 23, 1-25. doi:10.1016/j.pmcj.2014.12.009

Yin, C., Zhang, B., David, B., \& Xiong, Z. (2015). A hierarchical ontology context model for work-based learning. Frontiers of Computer Science, 9(3), 466-473. doi:10.1007/s11704-015-4200-4

Benmesbah Ouissem received his Master degree in computer science from the University of Constantine (Algeria) in 2017. SHe is currently working as an assistant teacher at the Computer Science Department of Annaba University, Algeria. She has several published papers in various books and international conferences. His current research interests are M-Learning, learning style and adaptive hypermedia. 